\title{
Correlation of Basketball Players' Physical Condition and Competition Activity Indicators
}

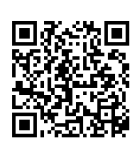

\author{
Uldis Gravitis* and Janis Rimbenieks \\ Department of Sports, Latvian Academy of Sport Education, Europe
}

Submission: January 20, 2018; Published: January 30, 2018

*Corresponding author: Uldis Gravitis, Department of Sports, Latvian Academy of Sport Education, Europe, Tel: +371 67543449;

Email: uldis.gravitis@lspa.lv

\begin{abstract}
We failed to find any research about whether physical condition affects the indicators of a basketball player's competition activity, and if yes, then to what extent; whether there is direct correlation between the indicators of a basketball player's physical condition and his shooting accuracy in a game, as well as the number of obtained and lost balls by him.
\end{abstract}

Aim of the research: To investigate correlation of basketball players' indicators of physical condition and competition activity. Male basketball players aged 21-25 years participated in the research. On the pre-game day all basketball players were tested. Players' heart rate was interpreted with the scientific device Omega M. A computer gave conclusion about a player's degree of tension, as well as the degree of adaptation to physical loads, the readiness of the body energy provision system, the degree of the body training and the psycho-emotional condition, as well as the total integral level of sports condition at the given moment. On the next day of the competition calendar game the content analysis of the competition technical recording was made to compare the player's whose physical indicators were lower performance with his average performance in the whole tournament.

Altogether 80 cases have been analysed when a player having lower physical condition indicators participated in a game. All in all the players having lower indicators of physical condition in $80 \%$ of cases competition activity results were lower than their average performance in the tournament. The Pearson's rank correlation coefficient also shows a close connection between the indicators of physical condition and competition activity $(\mathrm{r}=0.687$; $\mathrm{p}<0.01)$, in comparison to a player's average performance during the whole tournament.

Conclusion: Basketball players' indicators of physical condition have close correlation ( $r=0.687 ; \mathrm{p}<0.01)$ with the indicators of competition activity. The results of physical condition test obtained with the help of the device Omega $\mathrm{M}$ can be used to anticipate basketball players' performance of their competition activity.

\section{Introduction}

The indicators of basketball players' competition activity (shooting accuracy, obtained balls and as the number of personal fouls that opponent's get against the players of our team) are often different for the same players in different games. Coaches and players themselves explain it as the changes of physical condition. We failed to find any research about whether physical condition affects the indicators of a basketball player's competition activity, and if yes, then to what extent; whether there is direct correlation between the indicators of a basketball player's physical condition and his shooting accuracy in a game, as well as the number of obtained and lost balls by him. There is a lot of research concerning basketball players' competition activity and its development including problems in training young basketball players. There are also many researches about basketball players' physical conditioning in basketball [1-5].

Different training methods to improve physical condition have been researched [6,7]. However, interrelation between physical condition and competition activity results has not been studied. Russian researchers, having investigated heart rate variety, have developed practical recommendations for the evaluation of one's physical condition. Substantiating on these researches, the device Omega $M[8,9]$ has been worked out and applied practically when testing athletes and also astronauts' physical condition in definite time period.

Aim of the research: to investigate correlation of basketball players' indicators of physical condition and competition activity.

\section{Materials and Methods}

Players' heart rate was interpreted with the scientific device Omega M. Electronically analyzing applying modern information technologies, a computer gave conclusion about a player's degree of tension, as well as the degree of adaptation to physical loads, the readiness of the body energy provision system, the degree of the body training and the psycho-emotional condition, as well as the total integral level of sports condition at the given moment. These five basketball players' indicators of physical condition were expressed in per cent with $100 \%$ as complete readiness. 
The total evaluation of physical condition was expressed using five degree point system: 5 points were given if at least four of five indicators were on $70 \%$ level. If the basketball players' total evaluation in points was four and less, it was considered as quite low physical condition. A player received four points if two of five indicators were lower than $70 \%$. Male basketball players aged 21-25 years participated in the research. On the pre-game day all basketball players were tested. On the next day of the competition calendar game the content analysis of the competition technical recording was made to compare the player's whose physical indicators were lower performance with his average performance in the whole tournament.

Altogether 80 cases have been analysed when a player having lower physical condition indicators participated in a game. When studying the basketball players' present level of physical condition before each game by applying high technology medical equipment OMEGA C, along with the total body condition also separate parameters of the condition were examined. They are as follows:

a) The adaptation level of a basketball player's body to physical load, the level of being trained, the level of supply of power, and psycho-emotional condition.

b) Each of these parameters of body condition can probably affect a basketball player's competition results, as well as the quality of different game element execution.

c) From competition parameters the following are being researched: the accuracy of two point shots, three point shots and the foul shots, the number of rebounds in a game, as well as the number of personal fouls that opponents get against the players of our team.

d) Each of these parameters of competition activity can be affected by one or several parameters of the body condition level.

e) As the criterion for the indicator evaluation of the quality of the competition activity a player's average performance during all tournaments was taken. Those players whose indicators of physical condition were lower before the game were evaluated.

f) Comparing the data the Pearson's rank correlation coefficient was calculated.

\section{Results}

The participants' parameters of competition activity show a great variability from game to game. For example, the accuracy of two point shots is from $76.2 \%$ to $40.9 \%$, and in the parameters of three point shots there is similar variability: from $42.8 \%$ to $11.1 \%$. The accuracy of the foul shots is a little bit more stable - from $76.5 \%$ to $51.3 \%$ (Figure 1). The number of rebounds, as well as the number of opponents' personal fouls what shows a player's activity in offense are slightly more even parameters. The number of rebounds in a game is from 49 to 32 balls, but the number of opponents' personal fouls in a game is from 27 to 11 (Figure 2). Also the parameters of physical condition change from day to day. So, the parameter of the body adaptation load is from $99 \%$ to $37 \%$, the parameters of the body being trained change from $100 \%$ to $57 \%$, the parameters of the body supply of power are from $98 \%$ to $43 \%$, but the parameters of the basketball players' psycho-emotional condition are not stable, too, being from $99 \%$ to $36 \%$.

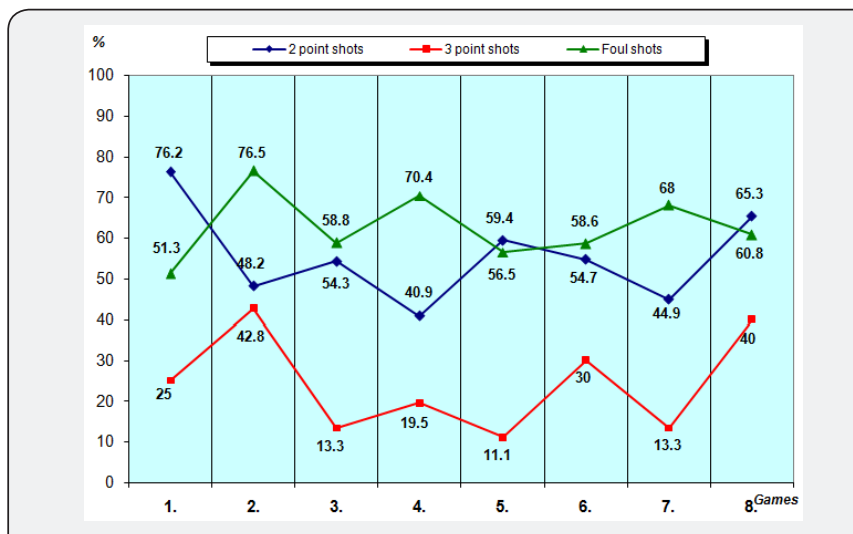

Figure 1: The parameters of shot accuracy.

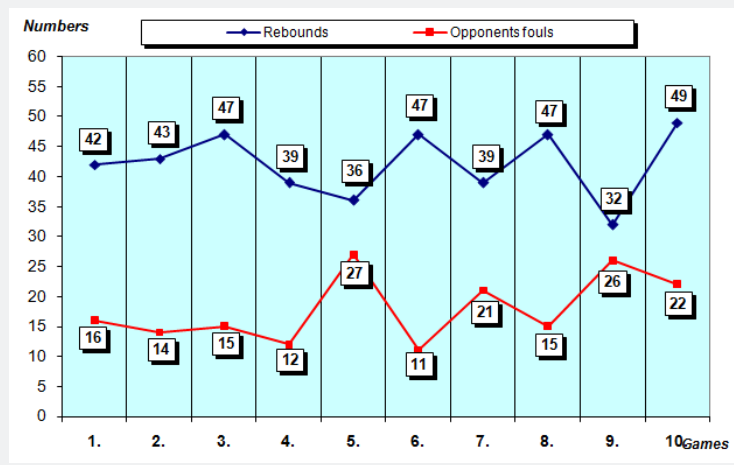

Figure 2: The parameters of competition activity.

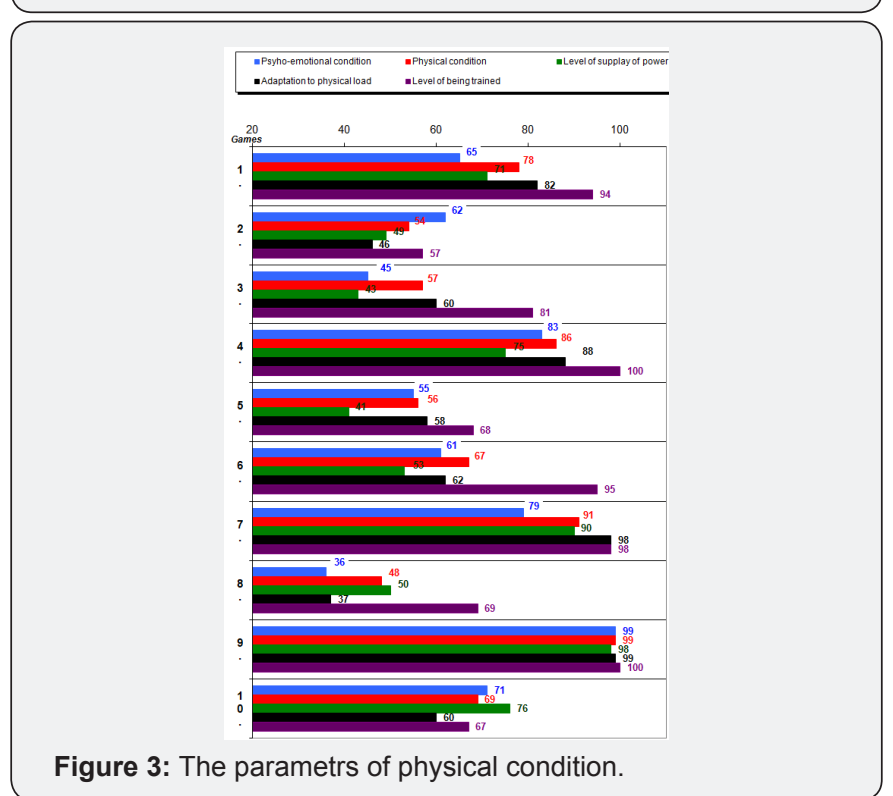

The parameter of the total athletic condition, definitely, is quite different when comparing one game to another - from 
$99 \%$ to $48 \%$ (Figure 3). The only parameter that correlates with the parameters of physical condition in total was the accuracy of shots. All in all the players having lower indicators of physical condition in $80 \%$ of cases competition activity results were lower than their average performance in the tournament. In $2.5 \%$ of the cases the players' having lower indicators of physical condition performance in competitions was in the level of their average indicators, but in $17.5 \%$ of the cases the players' indicators were better than their average performance in the tournament (Figure 4). The Pearson's rank correlation coefficient also shows a close connection between the indicators of physical condition and competition activity $(\mathrm{r}=0.687 ; \mathrm{p}<0.01)$, in comparison to a player's average performance during the whole tournament.

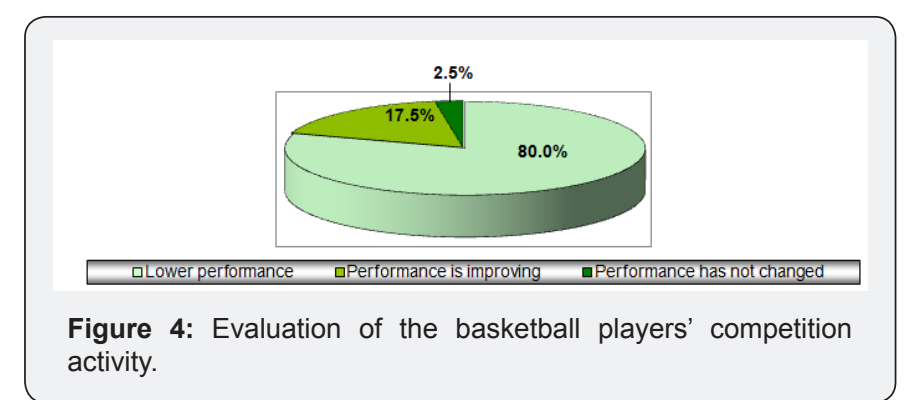

\section{Discussion}

The evaluation of the basketball players' competition activity performance consisted of seven different indicators, each of them showed different value changes depending on the level of different physical condition indicators. Similar thoughts have been expressed by Beashel P, Taylor J [6] and Chillious R [1] However, in our research we failed to find significant results about which physical condition indicators - the adaptation to physical load, level of the organism training degree, condition of the body energy provision system or psycho-emotional system-has a direct effect on players' accuracy of various shots and the number of the obtained or lost balls in a game. There is a clear tendency that physical condition parameters affect essentially the shooting accuracy. This opinion has been shared by different authors [10], also by Chillious [1]. In the research the question about the correlation of free throw accuracy and psycho-emotional condition remained on the level of hypothesis. There are authors who connect precision of free throw with psychological readiness, training. Chillious $\mathrm{R}$ [1] but there is a sports scientist who pays more attention to physical conditions when talking about precision of free throw [5, 11-15]. In this study with not so many stated cases significant results of the correlation of these two indicators have not been obtained. The research is being continued.

\section{Conclusion}

a) Basketball players' indicators of physical condition have close correlation $(r=0.687 ; p<0.01)$ with the indicators of competition activity.

b) In $80 \%$ of cases of lower physical condition players show indicators of their technical proficiency which are lower than their average proficiency level.

c) The results of physical condition test obtained with the help of the device Omega M can be used to anticipate basketball players' performance of their competition activities.

\section{References}

1. Chillious R (2010) The Shooting Matrix drill. FIBA Magazine Assist p. 4-8.

2. Mackenzie B (1997) Conditioning.

3. Mackenzie B (2003) Performance Profiling.

4. Davis B (2000) Training for physical fitness, Physical Education and the study of sport. Hartcourt Publishers, Spain.

5. Tancred B (1995) Key Methods of Sport Conditioning. Athletics Coach 29(2): 19.

6. Beashel P, Taylor J (1997) The World of Sport Examined. Thomas Nelson \& Sons Ltd, UK.

7. Mc Ardle W (2000) Essentials of Exercise Physiology. (2 ${ }^{\text {nd }}$ Edn) Lipincott Williams \& Wilkins, Philadelphia, USA.

8. Bajevsky MR, Ivanov GG, Ribkina GV (1999) Situation of modern research on variability of the heart rate, Arithmology newspaper 14: 71-75.

9. (2002) Variability of the heart rate: theoretical aspects and possibilities of clinical application. Institute of Biomedical Problems of MMA. Research laboratory Dynamics, Moscow, pp. 28.

10. Mc Ardle W (2000) Essentials of Exercise Physiology. (2 $2^{\text {nd }}$ Edn) Lipincott Williams \& Wilkins, Philadelphia, USA.

11. (2000) Basketball for young players: Guidelines for coaches, FIBA and EABC, München, Germany pp. 346.

12. Crust L (2002) Performance profiling a coaching tool for pinpointing strengths and weaknesses, designing training strategies and building better communication with athletes. Peak performance 183: 7-9.

13. Mackenzie B (1997) Endurance Training.

14. Gastin PB (2001) Energy system interaction and relative contribution during maximal exercise. Sports Med, 31(10): 725-741.

15. Mauffulli N, Merzesh M (2007) Genetic aspects of tendinopathy. Journal of Science and Medicine in Sport 11(3): 243-247. 


\section{Your next submission with Juniper Publishers}

will reach you the below assets

- Quality Editorial service

- Swift Peer Review

- Reprints availability

- E-prints Service

- Manuscript Podcast for convenient understanding

- Global attainment for your research

- Manuscript accessibility in different formats

( Pdf, E-pub, Full Text, Audio)

- Unceasing customer service

Track the below URL for one-step submission

https://juniperpublishers.com/online-submission.php 